\title{
NUTRITION OF THE ACETIC ACID BACTERIA
}

\author{
M. R. RAGHAVENDRA RAO AND J. L. STOKES \\ Department of Bacteriology, Indiana University, Bloomington, Indiana
}

Received for publication September 15, 1952

Relatively little information is available on the specific nitrogen and growth factor requirements of the acetic acid bacteria. The early observation of Hoyer (1898) and of Beijerinck (1898) that only Acetobacter aceti can develop in a mineral salts-ammonium nitrogen medium with ethanol plus acetate as the source of carbon has acquired taxonomic and diagnostic value for this and, more recently, other Acetobacter species. Frateur (1950) found that acetate is unnecessary if the medium is buffered adequately with phosphates. Hoyer and Beijerinck also noted that $A$. xylinum and $A$. rancens can grow with ammonium nitrogen if glucose is added to the ethanol medium. A similar nitrogen to carbon relationship may exist for A. pasteurianum and A. kützingianum. These organisms are considered by Frateur to be varieties of $A$. rancens and to be unable to develop in a medium containing ethanol and ammonium nitrogen. Kaushal and Walker (1951), however, obtained growth of both of these organisms as well as of $A$. acetigenum with ammonium nitrogen in a medium containing both ethanol and glucose. Ethanol alone is adequate for the growth of $A$. peroxydans (Visser't Hooft, 1925; Frateur, 1950) and $A$. lovaniense (Frateur, 1950) with ammonium nitrogen.

It is evident therefore that species other than $A$. aceti can utilize readily inorganic nitrogen for growth although for some strains this is possible only when glucose rather than ethanol is the source of carbon and energy.

But there is another nutritional aspect which needs to be considered. The above mentioned investigations were made with media which did not contain growth factors. It has long been known that media containing complex nitrogenous materials such as yeast extracts and peptones are necessary for the growth of many species of the genus Acetobacter including $A$. suboxydans, $A$. melanogenum, and $A$. rancens. With the development of knowledge of the growth factor requirements of microorganisms and the availability of the active compounds in pure form, a few attempts were made to determine the specific essential nutrients supplied by the complex natural materials of the medium. Thus, Underkofler, Bantz, and Peterson (1943) showed that a strain of $A$. suboxydans, ATCC 621, requires pantothenic, $p$-aminobenzoic, and nicotinic acids for growth in a medium containing casein hydrolyzate as the source of nitrogen and glycerol as the carbon source. This made it possible for Stokes and Larsen (1945) to establish that this strain of $A$. suboxydans requires a mixture of six amino acids for good growth and enabled them to grow $A$. suboxydans for the first time in a completely defined medium. Nitrogen in the form of ammonium salts was not adequate for growth, but at suboptimum concentrations of the required amino acids, it stimulated growth. Gray and Tatum (1944), however, noted that ammonium nitrogen is sufficient for growth of a strain of $A$. melanogenum, M.A. 6.1, if the growth factors thiamin, and pantothenic, nicotinic, and $p$-aminobenzoic acids were supplied in the medium. By x-ray irradiation Gray and Tatum obtained mutants which required amino acids for growth. These results suggest that species other than $A$. aceti, and those previously mentioned, may be able to grow with ammonium nitrogen if supplied with essential growth factors and with an appropriate source of carbon and energy.

The paucity of data on the specific growth factor and nitrogen requirements of species of the genus Acetobacter which develop only in the presence of complex nitrogenous materials prompted us to undertake the present investigations. The results obtained demonstrate that the ability to utilize ammonium nitrogen is much more widespread among the acetic acid bacteria than previously has been suspected; that a number of strains require apparently new and unidentified growth factors; and that the requirements for growth factors and nitrogen are influenced critically by the available source of carbon and energy. 


\section{MATERIALS AND METHODS}

Twenty-five strains representing $A$. xylinum, $A$. rancens, $A$. gluconicum, $A$. suboxydans, and $A$. melanogenum were used. The eleven strains of acetic acid bacteria identified by the prefix M.A. were kindly supplied by Dr. C. B. van Niel. The remaining fourteen strains were isolated from fruits, cider, beer, and fermented distillery mashes of corn, wheat, and milo. These were identified as strains of $A$. rancens, $A$. suboxydans, and $A$. melanogenum by means of the methodology and system of classification of Frateur (1950). The cultures were maintained on 2 per cent glycerol, 10 per cent yeast autolysate agar slants or on slants composed of 2 per cent glucose, 10 per cent yeast autolysate, and 2 per cent calcium carbonate.

The yeast autolysate was prepared by thoroughly suspending $1 \mathrm{lb}$ of baker's yeast in onehalf liter of water. The suspension was placed at $50 \mathrm{C}$ for $24 \mathrm{hr}$ to permit autolysis of the yeast to take place. Then it was boiled for a few minutes, adjusted to $\mathrm{pH} 7$ with $2 \mathrm{~N} \mathrm{NaOH}$, filtered through paper until clear (opalescent), and autoclaved.

Medium A, used in most of the experiments, had the following composition:

Ethanol, glucose, or other carbon source.

$\left(\mathrm{NH}_{4}\right)_{2} \mathrm{SO}_{4} \ldots \ldots \ldots \ldots \ldots \ldots \ldots \ldots$ or

Casein hydrolyzate (vitamin-free).....

(plus $10 \mathrm{mg}$ of L-cysteine and $20 \mathrm{mg}$ of DL-tryptophan)

Salt solution $\mathbf{A}^{*} \ldots \ldots \ldots \ldots \ldots \ldots \ldots$

Salt solution Bt.................

Vitamin mixture: $\mathbf{4 0} \mu \mathrm{g}$ each of thiamin

$\left(B_{1}\right)$, riboflavin $\left(B_{2}\right)$, nicotinic acid

(NA), and panthothenic acid (PA),

$80 \mu \mathrm{g}$ of pyridoxine $\left(\mathrm{B}_{6}\right), 10 \mu \mathrm{g}$ of $p$ -

aminobenzoic acid (PABA), $1 \mu \mathrm{g}$ of

pteroylglutamic acid (PGA), $0.1 \mu \mathrm{g}$ of

vitamin $B_{12}, 0.04 \mu \mathrm{g}$ of biotin, and 0.5

$\mathrm{mg}$ of inositol.

Distilled $\mathrm{H}_{2} \mathrm{O}$ to ................ $100 \mathrm{ml}$

Medium adjusted to $\mathrm{pH} 6.2$ to $\mathrm{pH} 6.5$.

-Salt solution A

$\mathrm{KH}_{2} \mathrm{PO}_{4} \ldots . .50 \mathrm{~g}$

$\mathrm{K}_{2} \mathrm{HPO}_{4} \ldots \ldots 50 \mathbf{g}$

$\mathrm{H}_{2} \mathrm{O} \ldots \ldots \ldots 500 \mathrm{ml}$

$\begin{array}{lr}\mathrm{MgSO}_{4} \cdot 7 \mathrm{H}_{2} \mathrm{O} \ldots \ldots & 20 \mathrm{~g} \\ \mathrm{NaCl} \ldots \ldots \ldots \ldots & \mathbf{1} \mathrm{g} \\ \mathrm{FeSO}_{4} \cdot 7 \mathrm{H}_{2} \mathrm{O} \ldots \ldots & 1 \mathrm{~g} \\ \mathrm{MnSO}_{4} \cdot 4 \mathrm{H}_{2} \mathrm{O} \ldots \ldots & 1 \mathrm{~g} \\ \mathrm{HCl}, \text { concentrated } \quad 1 \mathrm{ml} \\ \mathrm{H}_{2} \mathrm{O} \ldots \ldots \ldots \ldots \ldots .500 \mathrm{ml}\end{array}$

The variations in the carbon and nitrogen sources employed are indicated in the experiments and tables. In some instances the vitamins were omitted either singly or all together. The media were dispensed in $10 \mathrm{ml}$ quantities into $50 \mathrm{ml}$ Erlenmeyer flasks and autoclaved. Ethanol, sodium pyruvate, and other volatile or thermolabile compounds were sterilized separately by filtration.

Inocula were taken from cultures grown for $24 \mathrm{hr}$ to $36 \mathrm{hr}$ on glucose, yeast autolysate, $\mathrm{CaCO}_{3}$ agar slants. A small amount of growth from a slant was suspended in sufficient water to give a turbidity reading of 15 to 20 in the KlettSummerson photometer with a $640 \mathrm{~m}_{\mu}$ filter. One drop of suspension served as inoculum for a flask of medium. The cultures were incubated at $28 \mathrm{C}$ for 5 days. Growth was measured as turbidity in the photometer. Uninoculated medium was used to adjust the photometer scale to zero.

In order to simplify the presentation of some of the data, growth is recorded in some of the tables in terms of + to ++++ rather than as direct Klett scale values. For this purpose the following arbitrary scale was established and used: - for values less than 15 ; + for values between 15 and $50 ;++$ for values between 51 and $100 ;+++$ for values between 101 and 200; and ++++ for values greater than 200 .

\section{EXPERIMENTAL RESULTS}

None of the strains of acetic acid bacteria grew in a mineral medium with either $\left(\mathrm{NH}_{4}\right)_{2} \mathrm{SO}_{4}$ or casein hydrolyzate and ethanol. Identical results were obtained with all but one of the organisms when glucose was substituted for ethanol; $A$. xylinum grew with ammonium nitrogen, as originally noted by Hoyer, and also with hydrolyzed casein.

Strikingly different results were obtained, however, if vitamins were added to the medium. This is evident from the data presented in table 1. The addition of vitamins permitted the growth of no less than 8 of the 11 strains of $A$. suboxydans and also 2 of the 6 strains of $A$. melanogenum with either $\left(\mathrm{NH}_{4}\right)_{2} \mathrm{SO}_{4}$ or hydrolyzed casein. Three additional strains, $A$. suboxydans, M.A. 8.2, and A. melanogenum, M.A. 6.4 and 2, also grew but only with hydrolyzed casein. None of the strains, as previously indicated, grew in the absence of vitamins.

The mixture of 10 vitamins, however, is not adequate to support the growth of any of the strains of $A$. gluconicum and $A$. rancens or of 
A. suboxydans, 4 and 5 , and A. melanogenum, M.A. 6.3 and M.A. 6.5. These strains require other growth factors present in yeast autolysate. Also, even those strains which develop in the chemically defined medium grow much more extensively in yeast autolysate medium. As will be shown later (table 4) these latter strains develop more luxuriantly in chemically defined media with glycerol and other carbon sources than with glucose which was used in this experiment. strains although some are stimulated considerably by this vitamin. The remaining seven B-vitamins, thiamin, riboflavin, pyridoxine, vitamin $B_{12}$, pteroylglutamic acid, biotin, and inositol, had little or no effect on growth.

The stimulatory effect of $p$-aminobenzoic acid is accentuated to the point of becoming essential if the medium contains only pantothenic and nicotinic acids rather than the mixture of the vitamins. It can be seen from data in table 3 that practically no growth of $A$. suboxydans,

TABLE 1

Nitrogen and growth factor requirements of acetic acid bacteria

\begin{tabular}{|c|c|c|c|c|c|}
\hline \multirow{2}{*}{ ORGAMISY } & \multicolumn{5}{|c|}{ MITROGEN SOURCE* } \\
\hline & $\left(\mathrm{NH}_{4}\right)_{2} \mathrm{SO}_{4}$ & $\underset{\text { B-vitamins }}{\left(\mathrm{NH}_{4}\right) \mathrm{SO}_{4}}+$ & $\underset{\text { casein }}{\text { Hydrolyzed }}$ & $\begin{array}{c}\text { Hydrolyzed } \\
\text { casein }+ \\
\text { B-vitamins }\end{array}$ & $\begin{array}{c}\text { Yeast } \\
\text { autolysate }\end{array}$ \\
\hline Acetobacter xylinum, strain M.A. 5.2 & Pellicle & Pellicle & Pellicle & Pellicle & Pellicle \\
\hline $\begin{array}{l}\text { Acetobacter gluconicum, strains M.A. } \\
\text { 9.3, M.A. 9.4 }\end{array}$ & - & - & - & - & ++++ \\
\hline $\begin{array}{l}\text { Acetobacter rancens, strains M.A. } 7.1 \\
1,2,3,4\end{array}$ & - & - & - & - & ++++ \\
\hline \multicolumn{6}{|l|}{ Acetobacter suboxydans, strains } \\
\hline 4,5 & - & - & - & - & ++++ \\
\hline M.A. 8.2 & - & - & - & ++ & $+t+$ \\
\hline 6,8 & - & + & - & ++ & +++ \\
\hline M.A. 8.1, M.A. 8.3, 7 & - & ++ & - & ++ & +++ \\
\hline $1,2,3$ & - & ++ & - & +++ & ++++ \\
\hline \multicolumn{6}{|l|}{ Acetobacter melanogenum, strains } \\
\hline M.A. 6.3, M.A. 6.5 & - & - & - & - & +++ \\
\hline M.A. 6.4, 2 & - & - & - & ++ & ++++ \\
\hline M.A. 6.2 & - & + & - & ++ & ++++ \\
\hline 1 & - & +++ & - & ++ & $+t+t$ \\
\hline
\end{tabular}

* Medium A used with modifications as indicated and with glucose.

$\dagger$ Ten per cent of yeast autolysate in distilled water.

The specific vitamin requirements of the 10 strains of $A$. suboxydans and $A$. melanogenum which grew with $\left(\mathrm{NH}_{4}\right)_{2} \mathrm{SO}_{4}$ and hydrolyzed casein were determined first by eliminating one vitamin at a time from the mixture of ten. It is evident from the data in table 2 that omission of either pantothenic acid or nicotinic acid prevents any significant growth of the strains except that of $A$. suboxydans, strain 3. The latter grew extensively in the absence of nicotinic acid. $p$-Aminobenzoic acid is not essential in the presence of the other nine vitamins for any of the strains M.A. 8.1, 1, and 8, and A. melanogenum, strain M.A. 6.2, occurs in the absence of $p$ aminobenzoic acid even when nicotinic acid and pantothenic acid are present, and for these strains, therefore, $p$-aminobenzoic acid is essential. The apparent lack of essentiality of this vitamin for these 4 strains in the previous experiment (see table 2) might be due to the ability of one of the other vitamins to substitute for $p$-aminobenzoic acid in the nutrition of the acetic acid bacteria or to the presence of $p$ aminobenzoic acid as a contaminant in one or 
more of the other growth factors, especially inositol. Pteroylglutamic acid contains $p$-aminobenzoic acid in its molecular structure and therefore might be able to replace $p$-aminobenzoic acid nutritionally. But experimentally this does suboxydans, strain ATCC 621 (Underkofler et al., 1943), whereas for other strains $p$-aminobenzoic acid is merely stimulatory or inactive.

The data in table 3 also show that $A$. suboxydans, strain 3, can grow when supplied only

TABLE 2

Vitamin requirements of acetic acid bacteria

\begin{tabular}{|c|c|c|c|c|c|c|c|c|c|c|c|c|}
\hline \multirow{2}{*}{ ORGANTEY } & \multicolumn{12}{|c|}{ 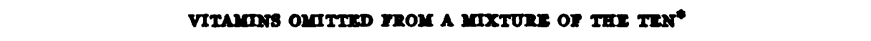 } \\
\hline & All & None & $\mathbf{P A}$ & NA & PABA & $\mathbf{B}_{\mathbf{1}}$ & $\mathbf{B}_{2}$ & B. & $\mathbf{B}_{\mathbf{1 2}}$ & PGA & Biotin & Inositol \\
\hline & \multicolumn{12}{|c|}{ Turbidity - Klett valwes } \\
\hline $\begin{array}{l}\text { Acetobacter suboxydans, strain M.A. } \\
8.1\end{array}$ & $\mathbf{0}$ & 140 & 2 & 8 & 70 & 152 & 144 & 150 & 119 & 142 & 132 & 119 \\
\hline $\begin{array}{l}\text { Acetobacter suboxydans, strain M.A. } \\
\text { 8.3 }\end{array}$ & $\mathbf{0}$ & 100 & $\mathbf{0}$ & 4 & 15 & 94 & 98 & 102 & 103 & 90 & 92 & 95 \\
\hline Acetobacter suboxydans, strain 1 & 0 & 144 & $\mathbf{0}$ & $\mathbf{0}$ & 119 & 127 & 130 & 137 & 128 & 112 & 115 & 134 \\
\hline Acetobacter suboxydans, strain 2 & $\mathbf{0}$ & 143 & 1 & 6 & 135 & 126 & 128 & 157 & 150 & 121 & 151 & 147 \\
\hline Acetobacter suboxydans, strain 3 & $\mathbf{0}$ & 168 & $\mathbf{0}$ & 132 & 45 & 165 & 174 & 184 & 170 & 175 & 150 & 156 \\
\hline Acetobacter suboxydans, strain 6 & $\mathbf{0}$ & 148 & $\mathbf{0}$ & $\mathbf{0}$ & 144 & 148 & 145 & 146 & 143 & 142 & 140 & 135 \\
\hline Acetobacter suboxydans, strain 7 & $\mathbf{0}$ & 119 & 1 & 0 & 102 & 103 & 127 & 91 & 85 & 97 & 120 & 93 \\
\hline Acetobacter suboxydans, strain 8 & $\mathbf{0}$ & 130 & 2 & 4 & 70 & 128 & 138 & 140 & 135 & 131 & 128 & 130 \\
\hline $\begin{array}{l}\text { Acetobacter melanogenum, strain } \\
\text { M.A. } 6.2\end{array}$ & 0 & 161 & 3 & 10 & 52 & 110 & 172 & 166 & 155 & 130 & 167 & 130 \\
\hline Acetobacter melanogenum, strain 1 & 0 & 103 & $\mathbf{0}$ & 2 & 98 & 95 & 104 & 110 & 100 & 85 & 98 & 105 \\
\hline
\end{tabular}

* Medium A with hydrolyzed casein and glucose was used.

TABLE 3

Specific vitamin requirements of acetic acid bacteria

\begin{tabular}{|c|c|c|c|c|}
\hline \multirow{2}{*}{ ORGANISY } & \multicolumn{4}{|c|}{ VITAMENS ADDED* } \\
\hline & All & $\mathbf{P A}+\mathbf{N A}$ & $\mathbf{P A}_{\text {PABA }}^{+N A}+$ & $\begin{array}{l}\text { PA + NA } \\
+ \text { PGA }\end{array}$ \\
\hline & \multicolumn{4}{|c|}{ Twrbidity - Klett valwes } \\
\hline Acetobacter suboxydans, strain M.A. 8.1 & 103 & 15 & 76 & 6 \\
\hline Acetobacter suboxydans, strain M.A. 8.3 & 105 & 7 & 98 & 4 \\
\hline Acetobacter suboxydans, strain 1 & 101 & 91 & 100 & 88 \\
\hline Acetobacter suboxydans, strain 2 & 141 & 146 & 138 & 133 \\
\hline Acetobacter suboxydans, strain 3 & 173 & $53 \dagger$ & 155 & 101 \\
\hline Acetobacter suboxydans, strain 6 & 120 & 106 & 108 & 97 \\
\hline Acetobacter suboxydans, strain 7 & 116 & 129 & 106 & 107 \\
\hline Acetobacter suboxydans, strain 8 & 111 & 8 & 118 & 5 \\
\hline Acetobacter melanogenum, strain M.A.6.2 & 126 & 7 & 39 & 3 \\
\hline Acetobacter melanogenum, strain 1 & 103 & 95 & 98 & 105 \\
\hline
\end{tabular}

* Medium A with casein hydrolyzate and glucose was used.

† Only pantothenic acid was present.

not occur. The difference in effect of $p$-aminobenzoic acid in the two experiments was not investigated further. But it can be concluded that some strains of $A$. suboxydans require $p$ aminobenzoic acid for growth in addition to pantothenic acid and nicotinic acid, as does $\boldsymbol{A}$. with pantothenic acid but grows best when nicotinic acid and $p$-aminobenzoic acid also are present. A. melanogenum, strain M.A. 6.2, is greatly stimulated by thiamin, and for good growth thiamin and $p$-aminobenzoic acid as well as pantothenic and nicotinic acids must be sup- 
plied. This strain, therefore, closely resembles strain M.A. 6.1 used by Gray and Tatum (1944) in their investigations and differs from strain 1 which requires only pantothenic and nicotinic acids.

In all of the experiments on vitamin requirements, similar results were obtained with both hydrolyzed casein and $\left(\mathrm{NH}_{4}\right)_{2} \mathrm{SO}_{4}$.

The 11 strains of $A$. gluconicum, $A$. rancens, $A$. suboxydans, and $A$. melanogenum are nutritionally the most exacting since they develop only in media containing yeast autolysate. $\mathrm{Ob}$ viously there are many known growth factors in addition to the ten which were used with negative results, and some of these might be the essential ones for the exacting strains. A large number of these other known growth factors, certainly most of them, were tested therefore for their effect on the growth of the exacting strains. They included the citrovorum factor, vitamin $C$, coenzyme $A$, antistiffness factor, lemon juice factor, ${ }^{1} \alpha$-lipoic acid, cocarboxylase, nicotinamide, pyridoxal, pyridoxamine, Armour's liver coenzyme preparation which contains diand triphosphopyridine nucleotides and pyridoxal and pyridoxamine phosphates; also choline, asparagine, glutamine, glutathione, ergosterol, adenine, guanine, xanthine, uracil, hypoxanthine, thymine, adenylic acid, guanylic acid, and cytidylic acid. Addition of these factors to medium A containing glucose, hydrolyzed casein, and the usual 10 vitamins failed to stimulate significantly the growth of the exacting strains. There was no evidence that the mixture of growth factors was toxic since a small amount of growth occurred in the basal medium and this was stimulated slightly by the supplement of growth factors. It seems reasonable to conclude therefore that these strains may require new and as yet unidentified growth factors.

As previously mentioned, the ability of many of the acetic acid bacteria to utilize ammonium nitrogen is dependent upon the carbon source available. Thus, $A$. xylinum develops with $\left(\mathrm{NH}_{4}\right)_{2}$ $\mathrm{SO}_{4}$ when glucose is in the medium but not with ethanol. And if the essential vitamins are provided, this same relationship has been demonstrated with 8 strains of $A$. suboxydans and 2 strains of $A$. melanogenum. In an attempt to obtain further information about this interesting nitrogen to carbon relationship, five of the above

1 Cf van Wagtendonk, Miller, and Conner (1952). mentioned strains of $A$. suboxydans and the two strains of $A$. melanogenum were examined for their ability to develop with $\left(\mathrm{NH}_{4}\right)_{2} \mathrm{SO}_{4}$, hydrolyzed casein, and yeast autolysate in media supplied with a variety of carbon sources: ethanol, propanol, butanol, the sodium salts of lactate, pyruvate, fumarate, and succinate, glucose, arabinose, mannitol, sorbitol, and glycerol. Little or no growth of any of the strains occurred with propanol, butanol, fumarate, and succinate. But the remaining compounds were utilized by at least some of the strains in the presence of one or more of the three nitrogen sources. Table 4 contains a typical cross section of the data obtained. The carbon compounds fall into two classes. One group permits growth with $\left(\mathrm{NH}_{4}\right)_{2} \mathrm{SO}_{4}$ and also with hydrolyzed casein and yeast autolysate and includes glycerol, mannitol, and sorbitol as indicated in the table and also glucose and arabinose. The second group consisting of ethanol, lactate, and pyruvate supports growth only in media containing yeast autolysate. Similar results were obtained with strains M.A. 8.1, M.A. 8.3, 3, and 7 of $A$. suboxydans and also with strain 1 of $A$. melanogenum. Thus, yeast autolysate supplies not only factors essential for the growth of the exacting strains but also contains a factor(s) necessary for the growth of many of the relatively less-exacting strains with $\left(\mathrm{NH}_{4}\right)_{2} \mathrm{SO}_{4}$ or hydrolyzed casein when ethanol, lactate, or pyruvate as the source of carbon.

The yeast autolysate factor cannot be replaced by a mixture of the known growth factors. The effect of increasing the concentrations of yeast autolysate upon the utilization of ethanol by two strains of $A$. suboxydans is shown in table 5. A minimum of about $10 \mathrm{mg}$ of the autolysate is necessary to obtain any appreciable increase in growth and acid formation; these increase progressively as the concentration of the yeast autolysate is increased to $100 \mathrm{mg}$ per $10 \mathrm{ml}$ of the medium. There is no doubt that the effect of yeast autolysate is to induce the utilization of ethanol since in the absence of ethanol much less growth and, more significantly, practically no acid are produced. The relatively large amounts of yeast autolysate required for appreciable utilization of ethanol suggest that either the active component(s) in the autolysate is present only in small amounts or that relatively large amounts of the factor are required by the bacteria. 
Similar results were obtained with the other strains which belong to this particular nutritional group of acetic acid bacteria.

It is known from exploratory experiments
It is water soluble, dialyzable, and cannot be extracted with ether at pH 2. Experiments are in progress to obtain further information on the nature of the factor.

TABLE 4

Influence of the carbon source on the growth of acetic acid bacteria with ammonium-nitrogen

\begin{tabular}{|c|c|c|c|c|c|c|c|}
\hline \multirow[b]{2}{*}{ ORGANISK } & \multirow[b]{2}{*}{ SOURCE OF NITROGEN } & \multicolumn{6}{|c|}{ SOURCE OF CARBON AND EMERGY" $\dagger$} \\
\hline & & Glycerol & Mannitol & Sorbitol & Ethanol & $\underset{\text { lactate }}{\mathrm{Na}}$ & $\underset{\substack{\text { pyru- } \\
\text { vate }}}{\mathrm{Naz}}$ \\
\hline Acetobacter suboxydans, strain 2 & $\begin{array}{l}\left(\mathrm{NH}_{4}\right)_{2} \mathrm{SO}_{4} \\
\text { Hydrolyzed } \\
\text { casein } \\
\text { Yeast autolysate }\end{array}$ & $\begin{array}{l}+++ \\
++++ \\
++++\end{array}$ & $\begin{array}{l}++++ \\
++++ \\
++++\end{array}$ & $\begin{array}{l}++++ \\
++++ \\
++++\end{array}$ & $\begin{array}{c}- \\
- \\
+++\end{array}$ & $\begin{array}{c}- \\
- \\
+++\end{array}$ & $\begin{array}{l}- \\
+ \\
++\end{array}$ \\
\hline $\begin{array}{l}\text { Acetobacter melanogenum, } \\
\text { strain M.A. 6.2 }\end{array}$ & $\begin{array}{l}\left(\mathrm{NH}_{4}\right)_{2} \mathrm{SO}_{4} \\
\text { Hydrolyzed } \\
\text { casein } \\
\text { Yeast autolysate }\end{array}$ & $\begin{array}{c}++ \\
+++ \\
+++\end{array}$ & $\begin{array}{c}++ \\
+++ \\
++++\end{array}$ & $\begin{array}{c}+t \\
+t \\
++t\end{array}$ & $\begin{array}{c}- \\
- \\
++\end{array}$ & $\begin{array}{c}- \\
- \\
+++\end{array}$ & $\begin{array}{r}- \\
- \\
++\end{array}$ \\
\hline
\end{tabular}

* Little or no growth occurred with any of the nitrogen sources in the absence of the carbon compounds.

$\dagger$ Medium A with 0.5 per cent sodium pyruvate and 2 per cent of the other carbon sources was used.

TABLE 5

Stimulatory effect of yeast autolysate on the utilization of ethanol by strains of Acetobacter suboxydans

\begin{tabular}{|c|c|c|c|c|c|c|c|c|c|c|}
\hline \multirow{4}{*}{ DETERYMNATION } & \multicolumn{10}{|c|}{ YEAST AUTOLYSATE, MG DRY WT } \\
\hline & \multicolumn{2}{|c|}{$\mathbf{0}$} & \multicolumn{2}{|c|}{1} & \multicolumn{2}{|c|}{10} & \multicolumn{2}{|c|}{35} & \multicolumn{2}{|c|}{100} \\
\hline & \multicolumn{10}{|c|}{2 per cent ethanol (E) present* } \\
\hline & $-\mathbf{E}$ & $+\mathbf{E}$ & $-\mathbf{E}$ & $+\mathbf{E}$ & $-\mathbf{E}$ & $+\mathbf{E}$ & $-\mathbf{E}$ & $+\mathrm{E}$ & $-\mathbf{E}$ & $+\mathbf{E}$ \\
\hline \multicolumn{11}{|c|}{ Acetobacter suboxydans, strain 2} \\
\hline $\begin{array}{l}\text { Turbidity } \ldots \ldots \ldots \ldots \ldots \ldots \\
\text { Acidity } t \ldots \ldots \ldots \ldots \ldots\end{array}$ & $\begin{array}{l}7 \\
0.0\end{array}$ & $\begin{array}{l}7 \\
0.0\end{array}$ & $\begin{array}{l}9 \\
0.0\end{array}$ & 11 & $\begin{array}{l}16 \\
0.0\end{array}$ & $\begin{array}{r}35 \\
1.5\end{array}$ & $\begin{array}{l}35 \\
0.1\end{array}$ & $\begin{array}{l}95 \\
2.7\end{array}$ & $\begin{array}{l}74 \\
0.2\end{array}$ & $\begin{array}{r}196 \\
4.4\end{array}$ \\
\hline \multicolumn{11}{|c|}{ Acetobacter suboxydans, strain M.A. 8.3 } \\
\hline $\begin{array}{l}\text { Turbidity ........ } \\
\text { Acidity } f . . . \ldots\end{array}$ & $\begin{array}{l}5 \\
0.0\end{array}$ & $\begin{array}{l}7 \\
0.1\end{array}$ & $\begin{array}{l}5 \\
0.0\end{array}$ & $\begin{array}{l}6 \\
0.2\end{array}$ & $\begin{array}{l}16 \\
0.0\end{array}$ & $\begin{array}{l}28 \\
0.8\end{array}$ & $\begin{array}{l}36 \\
0.1\end{array}$ & $\begin{array}{r}104 \\
3.7\end{array}$ & $\begin{array}{l}80 \\
0.2\end{array}$ & $\begin{array}{r}190 \\
4.5\end{array}$ \\
\hline
\end{tabular}

* Medium A with hydrolyzed casein was used.

$\dagger \mathrm{Ml}$ of $0.05 \mathrm{~N}$ acid per $\mathrm{ml}$ of culture; the theoretical value for the oxidation of all of the ethanol to acetic acid is $8.7 \mathrm{ml}$.

that this ethanol-also lactate and pyruvateutilization factor is present in pork and beef liver, in yeast extract (Difco) and tryptone, and in other biological materials. As present in yeast autolysate, the factor is a very stable compound since it is virtually unaffected by autoclaving at $121 \mathrm{C}$ for $1 \mathrm{hr}$ in $0.1 \mathrm{~N} \mathrm{H}_{2} \mathrm{SO}_{4}$ and $0.1 \mathrm{~N} \mathrm{NaOH}$.

\section{DISCUSSION}

The ability to grow with ammonium nitrogen is a primary characteristic for the classification of acetic acid bacteria and the identification of certain species, e.g., $A$. aceti, $A$. peroxydans, and $A$. lovaniense. The demonstration that this prop- 
erty is possessed also by strains of $A$. xylinum, $A$. rancens, $A$. suboxydans, and $A$. melanogenum and will perhaps be shown by future investigations to be a property of additional species of Acetobacter does not lessen its value for taxonomic purposes. For these latter species, growth factors and certain sources of carbon other than ethanol are necessary for the utilization of inorganic nitrogen, and these are lacking in Hoyer's medium, or modifications of it, which are routinely used in tests for utilization of ammonia. But it is important to note that the data obtained from such routine tests are of diagnostic value only and do not give a complete picture of the nutritional capacities of the strains. A strikingly parallel situation with yeasts has been observed by Wickerham (1946). Also yeasts have been classified on the basis of utilization of ammonia. But Wickerham showed that the usual tests for assimilation of ammonia merely measure the ability of the yeasts to synthesize certain B vitamins which are lacking in the test media commonly employed, for when the required vitamins were supplied all of the "negative" yeasts grew well with ammonium sulfate.

As is true for so many other nutritional requirements, those for the different forms of nitrogen vary greatly with the conditions of culture. In addition to the variations described in the present paper, many others concerned mainly with amino acids have been reported. Thus, Lactobacillus arabinosus requires phenylalanine, tyrosine, and aspartic acid for growth at $35 \mathrm{C}$ to $39 \mathrm{C}$, but these do not have to be supplied at $26 \mathrm{C}$ or if the atmosphere above the cultures is enriched with carbon dioxide (Lyman et al., 1947; Borek and Waelsch, 1951). Substitution of pyridoxamine for pyridoxine eliminates the requirement of Lactobacillus delbrueckii for lysine, threonine, and alanine (Stokes and Gunness, 1945), and biotin eliminates the need for aspartic acid in the case of Lactobacillus arabinosus and other lactic acid bacteria (Stokes, Larsen, and Gunness, 1947). Recently Ware (1951) has found that although ammonium nitrogen is adequate for the growth of Escherichia coli at $37 \mathrm{C}$, glutamic acid and nicotinamide must be supplied for growth at $44 \mathrm{C}$.

\section{ACKNOWLEDGMENTS}

We are greatly indebted to Dr. C. B. van Niel for providing us with many of the cultures and to Dr. W. J. van Wagtendonk of Indiana Uni- versity, Dr. E. L. R. Stokstad of the Lederle Laboratories, Dr. H. B. Woodruff of Merck and Company, and to the Armour Research Laboratories for generous supplies of some of the growth factors.

\section{SUMMARY}

The present investigations demonstrate that the ability to utilize ammonium nitrogen for growth is more widespread among the acetic acid bacteria than previously has been suspected. Many strains of Acetobacter suboxydans and Acetobacter melanogenum possess this property, but it becomes manifest only if two conditions are fulfilled: the medium must contain not only required growth factors but also appropriate sources of carbon and energy. Although the growth factor requirements vary somewhat with the individual strain, the demands of most strains of $A$. suboxydans are satisfied by pantothenic acid, nicotinic acid, and $p$-aminobenzoic acid; and those of $A$. melanogenum by these three vitamins plus thiamin. Suitable sources of carbon for these strains include glucose, arabinose, mannitol, sorbitol, and glycerol but not ethanol, pyruvate, and lactate. For growth with the latter three compounds, both with ammonium nitrogen and hydrolyzed casein, an unidentified factor(s) present in extracts of yeast, in tryptone, and other biological materials is required. Some properties of this factor are described.

All strains of Acetobacter gluconicum and Acetobacter rancens and some of $A$. suboxydans and $A$. melanogenum require apparently new and as yet unidentified factors which occur in yeast autolysate.

\section{REFERENCES}

Beiserinck, M. W. 1898 Ueber die Arten der Essigbakterien. Zentr. Bakt. Parasitenk. Abt. II, 4, 209-216.

Borex, E., AND WAELSCH, H. 1951 The effect of temperature on the nutritional requirements of microorganisms. J. Biol. Chem., 190, 191-196.

Frateur, J. 1950 Essai sur la systematique de Acetobacters. La Cellule, 63, 287-392.

Gray, C. H., and TATUM, E. L. 1944 X-ray induced growth factor requirements in bacteria. Proc. Natl. Acad. Sci. U. S., 30, 404410.

Horer, D. P. 1898 Beijdrage tot de Kennis van de Azijnbacterien. Dissertation, Delft.

KaUshax, R., AND WALKer, T. K. 1951 Forma- 
tion of cellulose by certain species of Acetobacter. Biochem. J., 48, 618-621.

Lyman, C. M., Moseley, O., Wood, S., Butuer, B., ANd HaLe, F. 1947 Some chemical factors which influence the amino acid requirements of the lactic acid bacteria. J. Biol. Chem., 167, 177-187.

Stokes, J. L., AND Gunness, M. 1945 Pyridoxamine and the synthesis of amino acids by lactobacilli. Science, 101, 43-44.

Stores, J. L., AND Larsen, A. 1945 Amino acid requirements of Acetobacter suboxydans. J. Bact., 49, 495-501.

Stores, J. L., Larsen, A., and Gunness, M. 1947 Biotin and the synthesis of aspartic by microorganisms. J. Bact., 54, 219230.

Underkofler, L. A., Bantz, A. C., and Peter- son, W. H. 1943 Growth factors for bacteria. XIV. Growth requirements of Acetobacter suboxydans. J. Bact., 45, 183-190.

van Wagtendonk, W. J., Miller, C. A., and CoNNER, R. L. 1952 Growth requirements of Paramecium aurelia, var. 4, stock 51.7(s) in a medium free of other living organisms. Federation Proc., 11, 302.

VIsser'T Hooft, F. 1925 Biochemische onderzoekingen over het geslacht Acetobacter. Dissertation, Delft.

WARE, G. C. 1951 Nutritional requirements of Bacterium coli at $44^{\circ}$. J. Gen. Microbiol., 5, 880-884.

Wickerham, L. J. 1946 A critical evaluation of the nitrogen assimilation tests commonly used in the classification of yeasts. J. Bact., 62, 293-301. 